\title{
TECHNIQUE OF ENDOVASCULAR RHEOLYTIC THROMBECTOMY USING ANGIOJET FOR TREATMENT OF ACUTE PULMONARY EMBOLISM
}

\author{
Paweł Latacz' ${ }^{1}$ Eugeniusz Majewski², Marek Piwowarczyk ${ }^{1}$ \\ 'Department of Vascular Surgery, University Hospital, Krakow, Poland \\ ${ }^{2}$ Faculty of Health Sciences, Medical University of Silesia, Katowice, Poland
}

\author{
TECHNICAL NOTE \\ Phlebological Review 2015; 23, 4: 106-109 \\ DOI: 10.5114/pr.2015.59019 \\ Submitted: 16.11 .2015 \\ Accepted: $\quad 30.12 .2015$ \\ ADDRESS FOR CORRESPONDENCE \\ Paweł Latacz \\ Department of Vascular Surgery \\ University Hospital, Krakow \\ Botaniczna 3, 31-503 Krakow \\ e-mail: pawlat@me.com
}

According to the American College of Chest Physicians (ACCP) guidelines [1], low-molecular weight heparin and fondaparinux are preferred treatment modalities for acute pulmonary embolism (PE). In addition, in selected patients these guidelines recommend thrombolytic therapy: in patients presenting with an acute PE associated with hypotension and also patients who reveal a high risk of developing hypotension. Of note, patients managed with fibrinolytic agents should not have a high bleeding risk.

Surgical embolectomy or endovascular removal of emboli can be an option in selected patients with submassive acute $\mathrm{PE}$, especially those with emerging hemodynamic or respiratory instability. Also, patients who do not improve after thrombolysis should be considered for surgical or endovascular embolectomy. Recent advances in endovascular techniques, such as aspiration thrombectomy, endovascular thrombus fragmentation devices and rheolytic or rotational thrombectomy, suggest that the endovascular approach can represent an alternative for pharmacological thrombolysis and surgical embolectomy. Endovascular treatment can be particularly advantageous when a surgical procedure is not available or thrombolytic management is contraindicated [1-5].

Importantly, endovascular procedures should be performed exclusively by doctors experienced with the techniques and armamentarium in this unique vascular territory.

Interventionalists should be aware of the fact that severe complications, comprising severe bleeding, cardiac tamponade, cardiogenic shock and bradyarrhythmias, are likely to develop during the procedure, and the med- ical team of the centre should be ready to manage these events. Dissection or perforation of the branches of the pulmonary artery with an endovascular device carries a high risk of fatal haemorrhage. Therefore, transcatheter embolectomy should be limited to the main pulmonary artery and lobar branches, since the risk of perforation significantly increases in vessels smaller than $6 \mathrm{~mm}$ [6-9].

In this technical note we describe the suggested approach to the catheter-based pulmonary thrombectomy using the rheolytic thrombectomy system AngioJet (Boston Scientific, Natick, MA, USA) [10].

\section{ENDOVASCULAR TECHNIQUE}

Femoral access is the preferred route for this procedure. The femoral vein should be cannulated with a $5 \mathrm{~F}$ or $6 \mathrm{~F}$ introducer sheath. Then, over the standard (for example InQwire Guide Wire, Merit Medical Systems) or hydrophilic (for example: 0.035" AqWire, Covidien, ev3 Endovascular, Inc., Plymouth, MN, USA) guidewire a pigtail diagnostic catheter should be positioned in the pulmonary trunk. This diagnostic catheter should be advanced into each pulmonary artery and pulmonary angiography should be performed (Fig. 1). Approximately 10-30 ml of contrast (the volume used should depend on the clinical status of the patient and the pulmonary pressure) is injected on each side. Injection of contrast should be followed by local administration of 5000 units of unfractionated heparin (the dose of heparin should be adjusted according to activated partial thromboplastin time and should be reduced if the drug has already been administered before the procedure). Once PE is 




Fig. 1. Initial angiography of the pulmonary arteries in a patient with pulmonary embolism (RPA - right pulmonary artery)

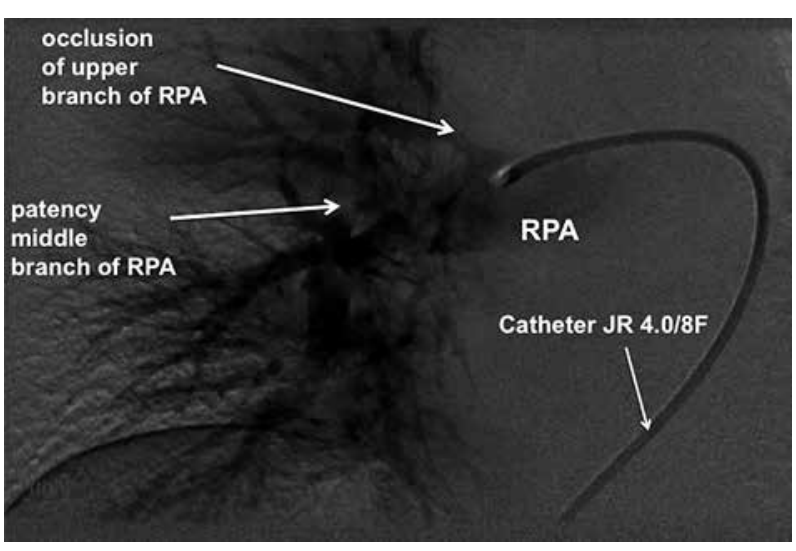

Fig. 3. Recanalisation of the middle branch of the right pulmonary artery after use of the AngioJet system

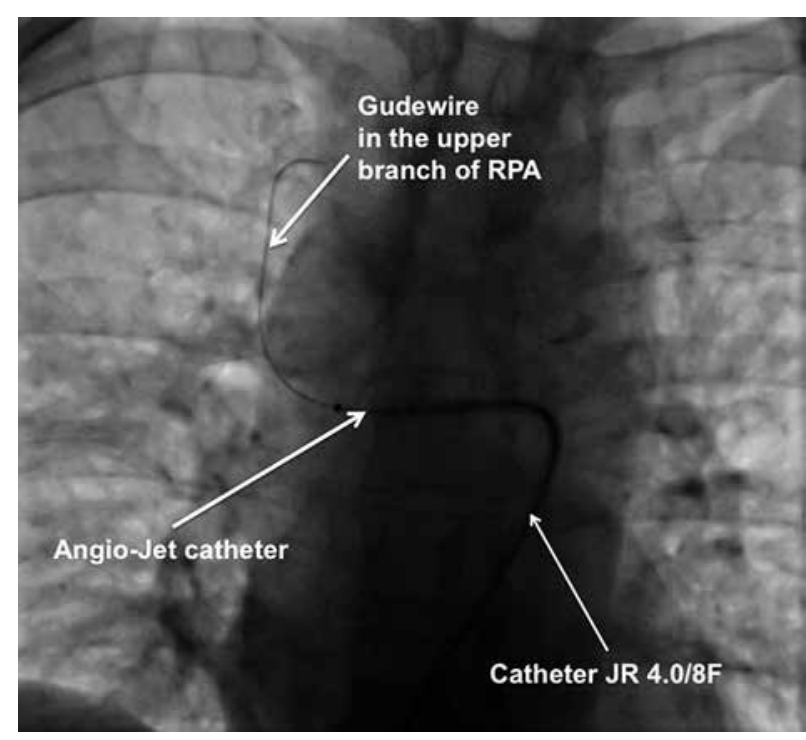

Fig. 5. Introduction of AngioJet system into the upper branch of the right pulmonary artery

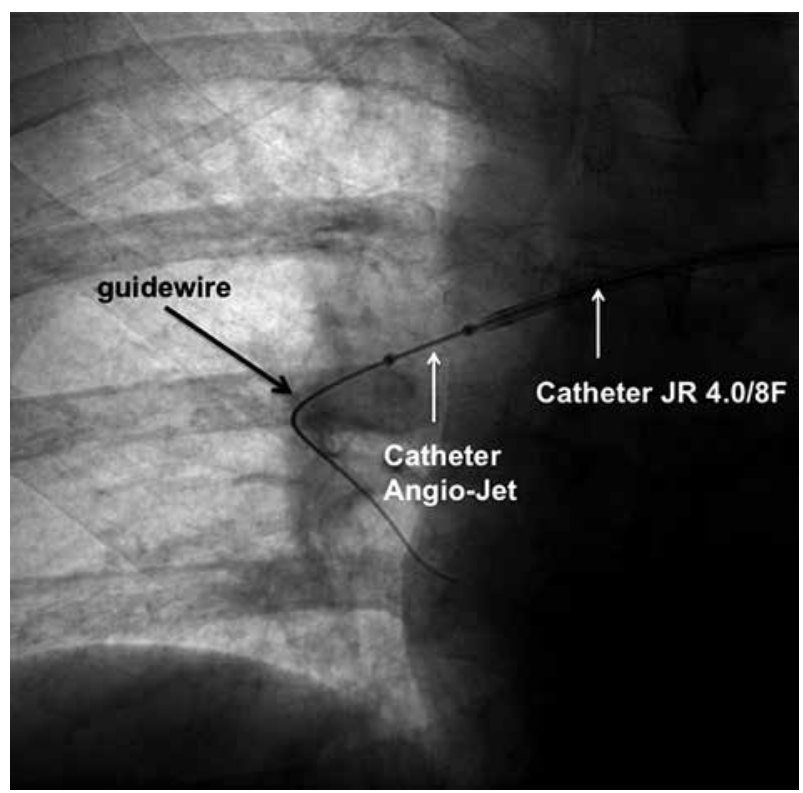

Fig. 2. Introduction of AngioJet system into the middle branch of the right pulmonary artery

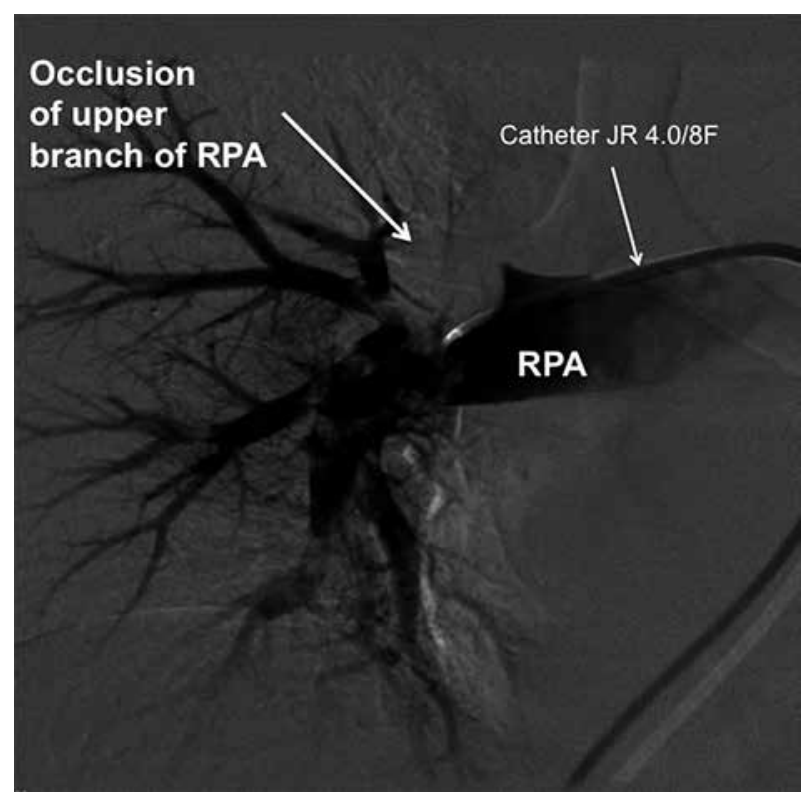

Fig. 4. Residual thrombi in the upper branch of the right pulmonary artery (RPA)

confirmed and a decision to address it using the rheolytic embolectomy is made, the introducer sheath should be replaced with a bigger one, preferentially an $8 \mathrm{~F}$ sheath. The embolus should be reached using a multipurpose $8 \mathrm{~F}$ guiding catheter (the AngioJet system is compatible with $6 \mathrm{~F}$ and $8 \mathrm{~F}$ catheters). We suggest using the SiteSeer Judkins Right catheter (Medtronic, Minneapolis, MN, USA) or a long sheath with a special tip, such as the Destination Guiding Sheath (Terumo, Tokyo, Japan). Through this guiding catheter, over a guidewire that should be navigated across the embolus (preferentially, a hydrophilic 


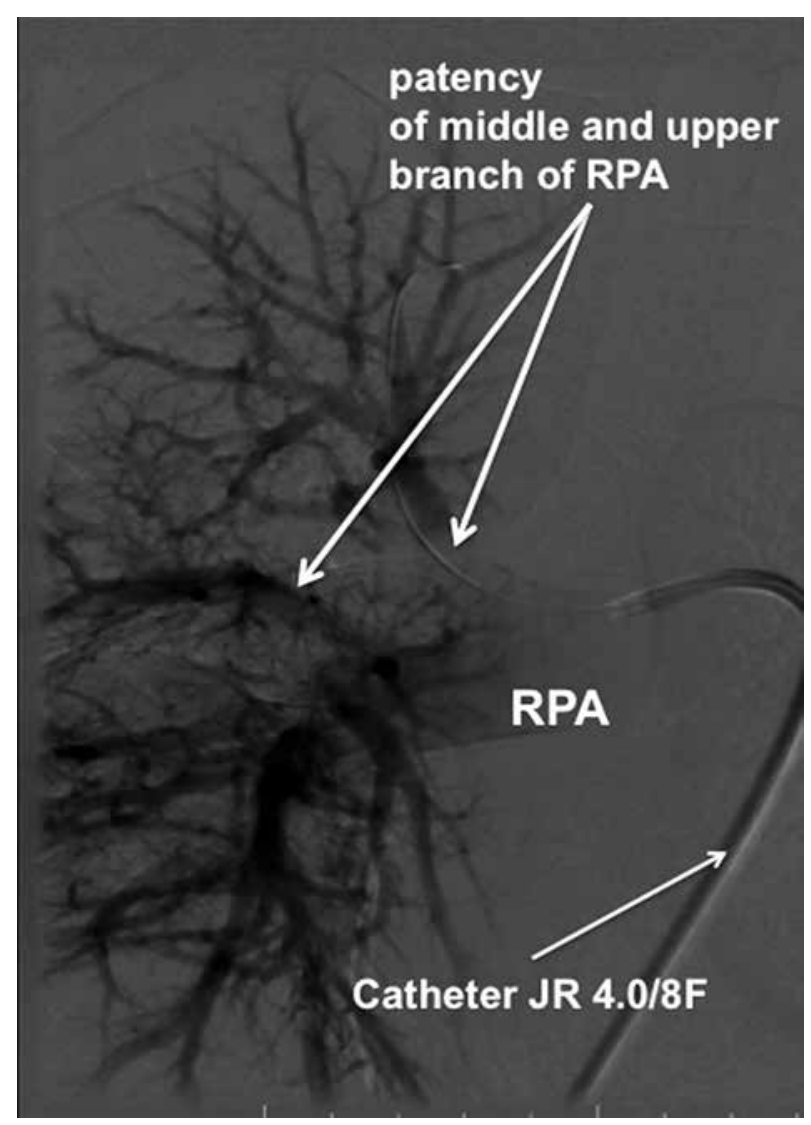

Fig. 6. Final result of the procedure in this patient (RPA - right pulmonary artery)

one, still advanced carefully), the AngioJet system (Boston Scientific, Natick, MA, USA) is introduced (Fig. 2). Using this endovascular device the emboli should be subsequently aspired from all occluded branches (Figs. 3-6). In general, embolectomy should be discontinued as soon as the patient's haemodynamic status stabilizes, even if the angiographic result is not perfect. As emphasized in the introduction, embolectomy of small branches of the pulmonary artery should be avoided, because navigation through these tiny vessels dramatically increases the risk of haemorrhage. If the above-described attempts to restore the patency of pulmonary arteries are not effective, direct local administration of a fibrinolytic agent (on condition that there are no contraindications for such treatment, especially intraprocedural injury of the artery) may be helpful. During aspiration of embolic material dyspnoea and cardiac decompensation can develop, especially if an aspiration lasts longer than 7-10 s. Thus, longer use of the AngioJet system should be avoided. Also, during the procedure some patients may develop bradyarrhythmias. Therefore, some authors recommend insertion of a temporary transvenous pacemaker. Careful preprocedural assessment of the patient should reveal whether such a pacemaker is indeed necessary. It should also be remembered that hemodynamic instability seen in PE patients, especially right ventricle overload, is not solely related to mechanical occlusion of pulmonary arteries, but also is associated with vasoconstriction of the pulmonary vasculature. Although the exact mechanism of such vasoconstriction in the setting of PE has not yet been elucidated, it is thought that haemolysis resulting from PE itself and also from pharmacological treatment with fibrinolytic agents reduces the concentration of nitric oxide (NO) in the pulmonary circulation through scavenging of NO by cell-free haemoglobin [11].

Perhaps other vasoactive substances, such as adenosine and bradykinin, may also play a role in the development of pulmonary vasoconstriction. Furthermore, severe haemolysis can lead to significant hyperkalaemia and also induce renal failure, which should be considered when managing PE patients.

The authors declare no conflict of interest.

\section{References}

1. Guyatt G.H., Akl E.A., Crowther M., Gutterman D.D., Schuünemann H.J.; American College of Chest Physicians Antithrombotic Therapy and Prevention of Thrombosis Panel. Executive summary: Antithrombotic Therapy and Prevention of Thrombosis, $9^{\text {th }}$ ed: American College of Chest Physicians Evidence-Based Clinical Practice Guidelines. Chest 2012; 141 (2 Suppl): 7S-47S

2. Konstantinides S.V., Torbicki A., Agnelli G., Danchin N., Fitzmaurice D., Galiè N., Gibbs J., Huisman M.V., Humbert M., Kucher N., Lang I., Lankeit M., Lekakis J., Maack C., Mayer E., Meneveau N., Perrier A., Pruszczyk P., Rasmussen L.H., Schindler T.H., Svitil P., Vonk Noordegraaf A., Zamorano J.L., Zompatori M.; Authors/Task Force Members. 2014 ESC Guidelines on the diagnosis and management of acute pulmonary embolism. Eur Heart J 2014; 35: 3033-3080.

3. De Gregorio M.A., Gimeno M.J., Mainar A., Herrera M., Tobio R., Alfonso R., Medrano J., Fava M. Mechanical and enzymatic thrombolysis for massive pulmonary embolism. J Vasc Interv Radiol 2002; 13: 163-169.

4. Jaff M.R., McMurtry M.S., Archer S.L., Cushman M., Goldenberg N., Goldhaber S.Z., Jenkins J.S., Kline J.A., Michaels A.D., Thistlethwaite P., Vedantham S., White R.J., Zierler B.K.; American Heart Association Council on Cardiopulmonary, Critical Care, Perioperative and Resuscitation; American Heart Association Council on Peripheral Vascular Disease; American Heart Association Council on Arteriosclerosis, Thrombosis and Vascular Biology. Management of massive and submassive pulmonary embolism, iliofemoral deep vein thrombosis, and chronic thromboembolic pulmonary hypertension: a scientific statement from the American Heart Association. Circulation 2011; 123: 1788-1830.

5. Latacz P., Rostoff P., Wyderka R., Rudnik A., Kondys M., Marut A., Buszman P., Piwowarska W. Massive pulmonary embolism mimicking ST elevation acute coronary syndrome successfully treated with hybrid therapy in a trauma patient receiving nadroparin: diagnostic and therapeutic dilemmas. Kardiol Pol 2007; 65: 1235-1242.

6. Bonvini R.F., Roffi M., Bounameaux H., Noble S., Müller H., Keller P.F., Jolliet P., Sarasin F.P., Rutschmann O.T., Bendjelid K., 
Righini M. AngioJet rheolytic thrombectomy in patients presenting with high-risk pulmonary embolism and cardiogenic shock: a feasibility pilot study. EuroIntervention 2013; 8: 14191427.

7. Bunwaree S., Roffi M., Bonvini J.M., Noble S., Righini M., Bonvini R.F. AngioJet ${ }^{\circ}$ rheolytic thrombectomy: a new treatment option in cases of massive pulmonary embolism. Interv Cardiol 2013; 5: 71-87.

8. Margheri M., Vittori G., Vecchio S., Chechi T., Falchetti E., Spaziani G., Giuliani G., Rovelli S., Consoli L., Biondi Zoccai G.G. Early and long-term clinical results of AngioJet rheolytic thrombectomy in patients with acute pulmonary embolism. Am J Cardiol 2008; 101: 252-258.

9. Vecchio S., Varani E., Nuzzo A., Balducelli M., Vecchi G., Aquilina M., Rubboli A., Margheri M. Percutaneous rheolityc thrombectomy with the Angio-Jet System for the treatment of intermediate-risk acute pulmonary embolism: a case report and an appraisal of contemporary indications and technique. Minerva Cardioangiol 2014; 62: 221-228.

10. Latacz P., Simka M., Ludyga T., Popiela T., Mrowiecki T. Endovascular thrombectomy with the AngioJet system for the treatment of intermediate-risk acute pulmonary embolism: a case report of two patients. Postep Kardiol Inter 2016; 1: 1-4.

11. Fuller B.M. Treatment of pulmonary embolism is all about relieving obstruction? N.O., it is not! Crit Care Med 2013; 41 1828-1829. 